\title{
Adhesion properties of styrene-butadiene rubber (SBR)/ Standard Malaysian Rubber (SMR L)-based adhesives in the presence of phenol formaldehyde resin
}

\author{
B. T. Poh*, L. N. Ong \\ School of Industrial Technology Universiti Sains Malaysia, 11800 Penang, Malaysia \\ Received 8 June 2007; accepted in revised form 7 August 2007
}

\begin{abstract}
The adhesion properties, i. e. viscosity, tack and peel strength of styrene-butadiene rubber (SBR)/Standard Malaysian Rubber (SMR L)-based pressure-sensitive adhesive was studied using phenol formaldehyde resin as the tackifying resin. Toluene was used as the solvent throughout the experiment. SBR composition in SBR/SMR L blend used was 0, 20, 40, 60, 80, 100\%. Three different resin loadings, i. e. 40, 80 and 120 parts per hundred parts of rubber (phr) were used in the adhesive formulation. The viscosity of adhesive was determined by a HAAKE Rotary Viscometer whereas loop tack and peel strength of paper/polyethylene terephthalate (PET) film were measured using a Lloyd Adhesion Tester operating at $30 \mathrm{~cm} / \mathrm{min}$. Results indicate that the viscosity of adhesive decreases with increasing \% SBR whereas loop tack passes through a maximum value at $20 \%$ SBR for all resin loadings. Except for the control sample (without resin), the peel strength shows a maximum value at $60 \%$ SBR for the three modes of peel tests. For a fixed $\%$ SBR, adhesive sample containing $40 \mathrm{phr}$ phenol formaldehyde resin always exhibits the highest loop tack and peel strength, an observation which is associated to the optimum wettability of adhesive on the substrate.
\end{abstract}

Keywords: rubber, adhesion, coating, tackifier

\section{Introduction}

Recently, we have carried out several investigations on the viscosity, tack, peel and shear strength of natural rubber (NR) and epoxidized natural rubber (ENR) [1-5]. It has been shown that the viscosity and tack of natural rubber-based adhesive increases with resin content due to the concentration effect of tackifier resin. The peel strength generally increases with resin content, an observation which is attributed to the wettability of substrates. On the other hand, shear strength of the adhesive decreases gradually with increasing resin content as a result of decreasing cohesive strength of adhesive as resin loading is increased. For a fixed resin content, shear strength increases with increasing coating thickness suggesting that shear strength is thickness-dependent. With regard to ENR-based pressure-sensitive adhesives, results show that peel strength passes through a maximum at $40 \mathrm{phr}$ of tackifying resin. However, the shear strength indicates a gradual decrease with increasing resin loading due to the decrease in cohesive strength of adhesive. ENR 25 consistently exhibits higher peel strength and shear strength than ENR 50. The viscosity and loop tack of ENR-based adhesive increases with increasing zinc oxide concentration. For the peel strength, it increases with zinc oxide concentration up to 30-40 phr of filler and drops after the maximum value. However, with respect to the effect of rubber blending on the adhesion property of pressure-sensitive adhesives, there is no study reported so far. We have thus carried out a 
systematic investigation to evaluate the effect of \% SBR on the viscosity, tack and peel strength of SBR/SMR L-based pressure sensitive-adhesive.

\section{Experiment}

\subsection{Materials}

SMR L grade was used as the natural rubber. The technical specification [6-7] of the rubber is given in Table 1.

Table 1. Technical specifications of SMR L

\begin{tabular}{|l|c|}
\hline Dirt content (max. \%wt) & 0.03 \\
\hline Ash content (max. \%wt) & 0.50 \\
\hline Nitrogen (max. \%wt) & 0.60 \\
\hline Volatile matter (max. \%wt) & 0.80 \\
\hline Plasticity retention index (min. \%) & 30 \\
\hline Mooney viscosity, $\mathrm{M}_{\mathrm{L}, 1+4}\left(100^{\circ} \mathrm{C}\right)$ & 78 \\
\hline
\end{tabular}

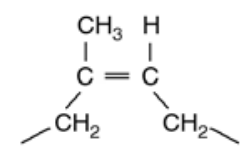

Figure 1. Structure of SMR L

The molecular structure of SMR L is given in Figure 1. It is a repeating unit of isoprene monomer to form $c i s-1,4$ polyisoprene.

Buna Hüls 1502 grade SBR was supplied by Bayer. It has a $33.5 \%$ by weight of target bound styrene. The density, ash content, Mooney viscosity and volatile matter of the rubber are $0.9 \mathrm{~g} / \mathrm{cc}, 0.5 \%, 50$ and $0.2 \%$ respectively.

Commercial grade phenol-formaldehyde resin was chosen as the tackifier. Its specific gravity, refractive index and specific heat are 1.2, 1.6 and 0.5 respectively. Toluene was used as the solvent throughout the study to prepare the rubber-based pressure-sensitive adhesives.

\subsection{Adhesive preparation}

The rubbers were masticated on a 2-roll mill for 10 minutes. Different blend ratios of SBR/SMR L corresponding to $0,20,40,60,80$ and $100 \%$ SBR were prepared. For each adhesive formulation, $5 \mathrm{~g}$ of the rubber blend was used. The rubber blend was then dissolved in $30 \mathrm{ml}$ of toluene. The rubber solution was kept in a conditioned room for 24 hours before the addition of phenol-formaldehyde resin. In order to study the effect of phenol-formaldehyde concentration on the adhesion properties, three dif- ferent weights i.e. 2, 4 and $6 \mathrm{~g}$ corresponding to 40 , 80 and 120 parts per hundred parts of rubber [phr] of resin were added to the rubber solution to prepare the adhesives. After the addition of resin, constant stirring with glass rod was carried out to ensure a homogeneous adhesive was formed. The adhesive was left for at least 3 hours prior to testing.

\subsection{Testing}

\subsubsection{Viscosity}

The viscosity of adhesive was measured by a HAAKE Rotary Viscometer (Model PK 100). Both the platform and the spindle head were cleaned with isopropyl alcohol to prevent contamination of the adhesive to be tested. Then, a little adhesive was dribbled onto the testing surface as well as the spindle head. The platform was raised up to touch the spindle head. Any excess adhesive was wiped off with a clean tissue and testing was carried out for one minute or ten rounds of spinning. At least five readings were taken and the average viscosity was computed.

\subsubsection{Tack}

Loop tack test is essentially a peel test involving low contact pressure and short application time [8]. A PET film with dimension of $4 \mathrm{~cm} \times 25 \mathrm{~cm}$ was coated at the centre of the film $(4 \mathrm{~cm} \times 4 \mathrm{~cm})$ with a coating thickness of $60 \mu \mathrm{m}$ using a SHEEN Hand Coater. The coated surface area was covered by a release paper and conditioned at room temperature for 30 minutes prior to testing. Then, a loop configuration with the adhesive exposed was formed after the removal of release paper. The top of the loop was taped and clamped in a Lloyd Adhesion Tester (Model LRXPlus with NEXYGEN software). The clamp was lowered at a constant speed of $10 \mathrm{~cm} / \mathrm{min}$ until the adhesive area touched the glass panel. The contact area was made without any force other than the pushing force of the loop. The loop was then pulled at $30 \mathrm{~cm} / \mathrm{min}$ until debonding from the glass panel occurred. The three highest peaks from the load-propagation graph were taken to calculate the average debonding force. The loop tack value is expressed as the debonding force per area of contact $\left[\mathrm{N} / \mathrm{m}^{2}\right]$. 


\subsubsection{Peel strength}

The substrates used for the peel tests were PET film and release paper which formed the base stock and face stock respectively. Three testing modes, i. e. T-Peel, $90^{\circ}$ and $180^{\circ}$ Peel Tests were used to determine the peel strength of adhesives. The dimensions of the substrates for the T- and $90^{\circ}$ Peel Tests were $20 \mathrm{~cm} \times 4 \mathrm{~cm}$. In the case of $180^{\circ}$ Peel Test, the dimensions of PET film and paper substrates were $25 \mathrm{~cm} \times 4 \mathrm{~cm}$ and $12 \mathrm{~cm} \times 6 \mathrm{~cm}$ respectively. A SHEEN Hand Coater was used to coat the PET film at $60 \mu \mathrm{m}$ thickness from the end of the film with a coating area of $10 \mathrm{~cm} \times 4 \mathrm{~cm}$. The coated PET film was covered by the paper substrate. The testing sample was then conditioned at room temperature for 24 hours before testing on a Lloyd Adhesion Tester operating at $30 \mathrm{~cm} / \mathrm{min}$. As in the case of tack determination, the three highest peaks from the load-propagation graph were recorded to compute the average peeling force. Peel strength is defined as the average load per width of the bondline required to separate progressively a flexible member from a rigid member or another flexible member (ASTM D 907).

\section{Results and discussion}

The effects of blend ratio and phenol formaldehyde resin loading on the viscosity, tack and peel strength of the pressure-sensitive adhesives prepared from SBR/SMR L blends are discussed below.

\subsection{Viscosity of adhesive}

Figure 2 shows the dependence of viscosity of adhesive on the \% SBR for various phenol formaldehyde resin loadings. It is obvious that all resin loadings (including the control sample), the

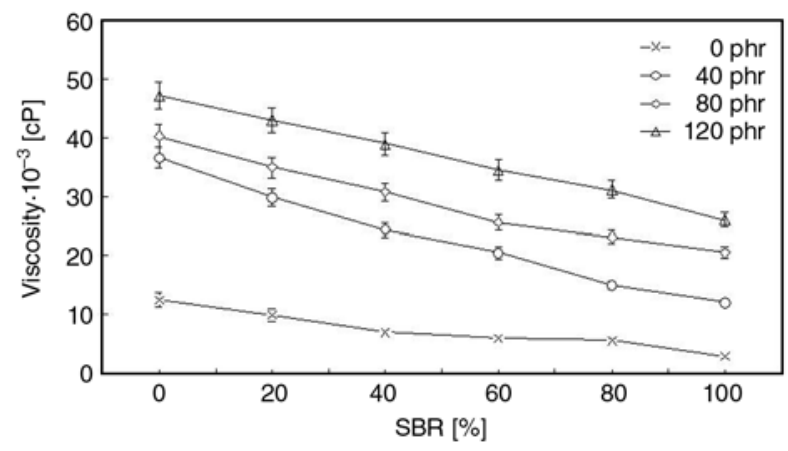

Figure 2. Dependence of viscosity with \% SBR for various resin loadings viscosity of adhesive decreases gradually with SBR composition. This observation is explained by lower molecular weight of SBR (Mooney viscosity $=50$ ) compared to that of SMR L (Mooney viscosity $=78$ ). Figure 2 also indicates that viscosity of adhesive increases with increase in resin loading. This observation is consistent with our previous study on SMR 10 and SMR 20-based pressure-sensitive adhesives [1-2]. The concentration effect of the tackifying resin accounts for this increase in viscosity. It is also observed that there is a significant increase in viscosity from $0-40 \mathrm{phr}$ of resin loading, especially below $60 \%$ SBR composition. This sudden increment may be attributed to the onset of chain entanglement [9] between SMR L and phenol formaldehyde resin. Further addition of resin is accompanied by the steady increase in viscosity as shown by the 80 and $120 \mathrm{phr}$ resin loading. This is especially so when SBR composition is increased beyond $60 \%$. In this case, chain entanglement does not govern the increase in viscosity as resin loading is increased. In other words, SBR chain does not entangle with the resin molecule and increment in viscosity is essentially a concentration effect phenomenon.

\subsection{Loop tack}

The dependence of loop tack on \% SBR for various resin loadings is shown in Figure 3.

For all resin loadings, loop tack increases with \% SBR to a maximum value at $20 \%$ SBR composition, after which it decreases with increasing $\%$ SBR. The maximum tack value observed at $20 \%$ SBR is attributed to the maximum wettability of adhesive on the substrate. At this condition, the adhesive is able to wet and conforms to the irregularities of the substrate, i.e. low surface energy condition is observed [10]. The surface energy of the

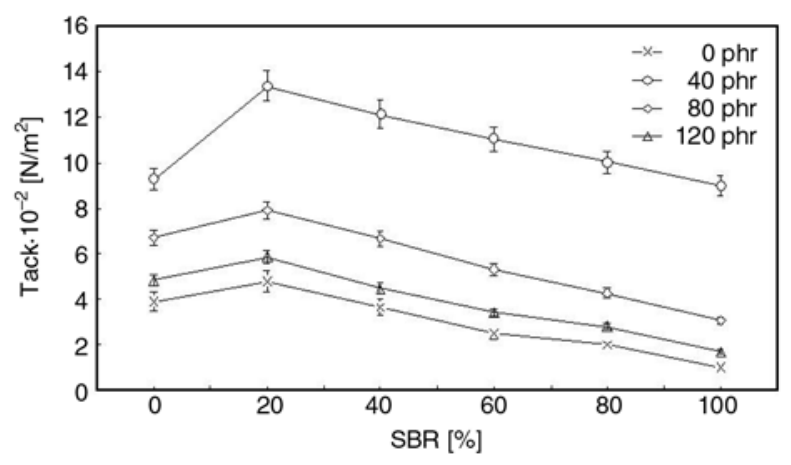

Figure 3. Dependence of loop tack with \% SBR for various resin loadings 
adhesive depends on the composition as shown by the variation of tack with \% SBR and phenolformaldehyde resin content. As \% SBR is further increased, tack value decreases correspondingly. This observation is associated with the lower flexibility property of SBR due to its lower $T_{g}\left(-53^{\circ} \mathrm{C}\right)$ [11] compared to that of SMR L $\left(T_{g}=-72^{\circ} \mathrm{C}\right)$. Figure 3 also indicates that for a fixed $\%$ SBR, maximum tack is consistently exhibited by the $40 \mathrm{phr}$ resin loading. At this resin loading, the optimum composition of adhesive is achieved which results in optimum wettability of adhesive. However, if resin loading is increased beyond $40 \mathrm{phr}$, a decrease in the tack value is obtained. This is due to the decreasing wettability of adhesive as resin component becomes a dominant component in the adhesive system, i. e. phase inversion occurs. The lowest tack value is shown by the control sample where no resin is added. This means that poor adhesion property is observed in the absence of tackifying resin such as phenol formaldehyde suggesting low wettability of adhesive.

\subsection{Peel strength}

The peel strength between paper/PET film using a T-Peel test mode is shown in Figure 4.

No plateau level is reached during crack propagation because the surface of substrate is not perfectly smooth. The irregularities on the surface of substrate (PET and release paper) explain why peaks occur during peel test. Debonding is observed between adhesive and release paper. The position of peaks changes with adhesive composition. Except for the control sample, maximum peel strength is observed at $60 \%$ SBR for the resinloaded adhesives. Owing to the difference in the substrate systems, maximum peak position for loop tack study (Figure 3) and that of peel strength (Fig-

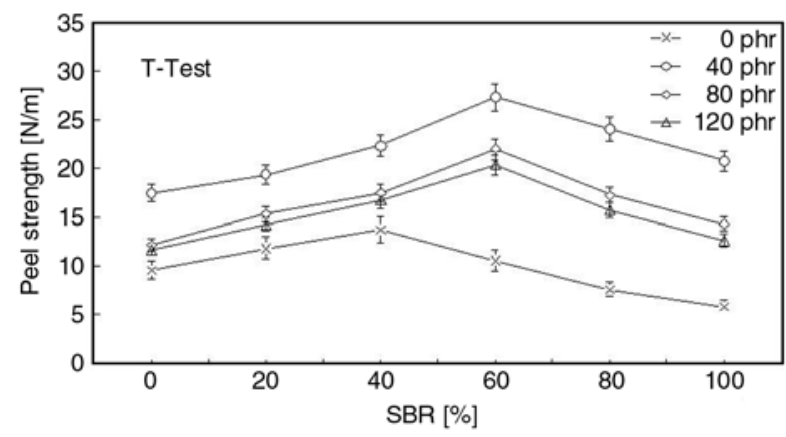

Figure 4. Dependence of peel strength (T-test) with \% SBR for various resin loadings ure 4) occurs at different positions. This observation is attributed to the difference in compatibility between the adhesive and substrates. However, for the control sample in the absence of phenol formaldehyde resin, maximum wettability occurs at lower \% SBR, i. e. at 40\% SBR. In all cases, peel strength drops after the maximum value which is due to the decrease in wettability with increase in \% SBR. For a fixed \% SBR, it indicates that after $40 \mathrm{phr}$ of phenol-formaldehyde resin content, a decrease in peel strength is obtained. This observation suggests that phase inversion occurs between 40-80 phr of the resin. The drop in peel strength with further addition of resin is attributed to the dilution effect, resulting in a decrease in modulus, i. e. resistance to rupturing of the bond is decreased. The peel strength for the $90^{\circ}$ and $180^{\circ}$ Peel Tests are shown in Figures 5 and 6 respectively. Except for the control sample, the figures also indicate that maximum peel strength occurs at $60 \%$ SBR for all the resin loadings studied. All these observations may be explained by the varying degree of compatibility of adhesive with substrate following changes in the adhesive formulation. Figure 7 shows the comparison of peel strength obtained from the three modes of peel tests at $60 \%$ SBR.

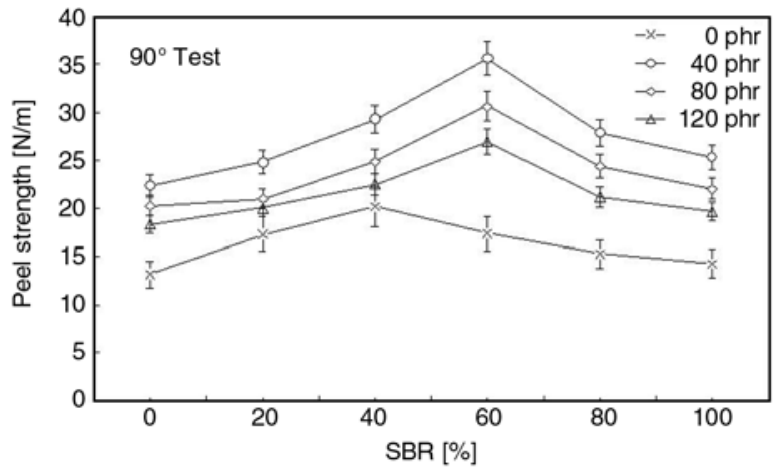

Figure 5. Dependence of peel strength $\left(90^{\circ}\right.$ test) with $\%$ SBR for various resin loadings

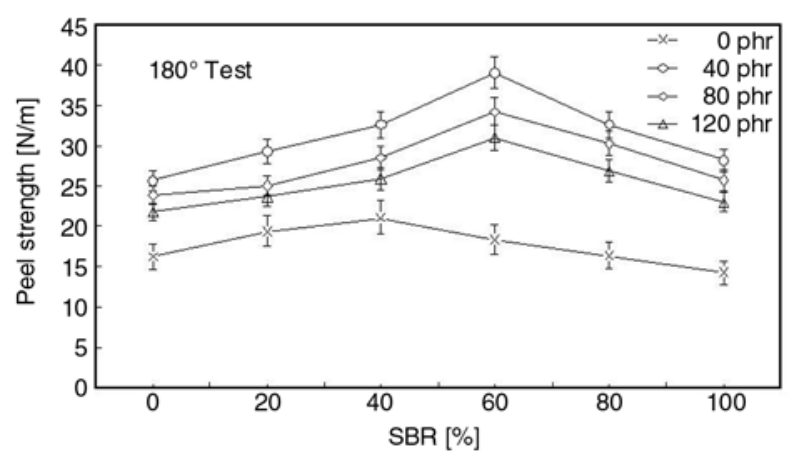

Figure 6. Dependence of peel strength $\left(180^{\circ}\right.$ test) with $\%$ SBR for various resin loadings 


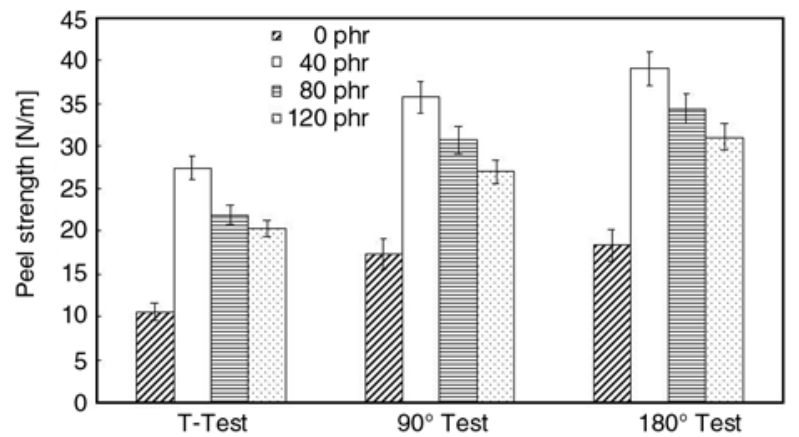

Figure 7. Comparison of peel strength between resin loadings for various peel tests at $60 \%$ SBR

The results also reveal that $180^{\circ}$ Peel Test consistently exhibits the highest peel strength for all phenol formaldehyde loadings, including the control sample. The difference in results is attributed to the difference in the angle of testing where a higher peel force is needed in the case of $180^{\circ}$ Peel Test. The rubber chains undergo more strain-induced crystallization [12-13] in the $180^{\circ}$ Peel Test compared to $\mathrm{T}$ - and $90^{\circ}$ Peel Tests. In other words, the adhesive hardens at high strain levels to become a tough solid and the adhesive layer itself cannot easily be ruptured [6]. Therefore, higher peel strength is needed in the case of $180^{\circ}$ Peel Test. Figure 7 also shows that the highest peel strength is exhibited by $40 \mathrm{phr}$ resin loading for the three modes of peel tests carried out in this study. Adhesive deformation in the bonding stage should be viscous to conform to the irregularities of the substrate. A high modulus during bond rupture will increase the tack and peel strength of adhesive. From this study, it is observed that the optimum viscosity occurs at $2.2 \times 10^{4} \mathrm{cP}$ where maximum peel strength is observed at $60 \%$ SBR and $40 \mathrm{phr}$ phenol-formaldehyde resin content. At this particular composition, maximum wettability and compatibility occur resulting in mechanical interlocking and anchorage of the adhesive in pores and irregularities in the substrate $[8,14]$, hence the highest peel strength is observed.

\section{Conclusions}

From this study, the following conclusions can be drawn.

1. The viscosity of adhesive decreases gradually with increase in SBR composition, an observation which is attributed by lower molecular weight of SBR compared to that of SMR L.
Below 60\% SBR composition, significant increase in viscosity from $0-40 \mathrm{phr}$ of phenol formaldehyde resin loading occurs, an observation which is associated to the onset of chain entanglement between SMR L and phenol formaldehyde resin.

2. Loop tack increases with \% SBR up to a maximum value at $20 \%$ SBR composition, after which it decreases with increasing \% SBR. The maximum tack value observed at $20 \%$ SBR is ascribed to the maximum wettability of adhesive on the substrate. For a fixed \% SBR, maximum tack is observed at $40 \mathrm{phr}$ resin loading after which tack value drops with further resin loading due to phase inversion.

3. Except for the control sample, maximum peel strength is observed at $60 \%$ SBR and $40 \mathrm{phr}$ of phenol formaldehyde resin loading for all the three modes of peel tests carried out in this study indicating that maximum wettability and compatibility occur at this composition. The highest peel strength is shown by the $180^{\circ}$ Peel Test for all phenol formaldehyde loadings, including the control sample. This observation is attributed to the higher strain-induced crystallization of rubber chain during $180^{\circ}$ peel test, hence causing the adhesive to harden and become a tough solid which cannot be ruptured easily.

\section{Acknowledgements}

The authors acknowledge the short-term research grant provided by Universiti Sains Malaysia that has resulted in this article.

\section{References}

[1] Poh B. T., Chang Y. Y.: Viscosity and peel strength of SMR 10-based pressure-sensitive adhesives. PolymerPlastics Technology and Engineering, 45, 1251-1256 (2006).

[2] Poh B. T., Chee C. L.: Effect of coumarone-indene resin on adhesion property of SMR 20-based pressuresensitive adhesives. International Journal of Polymeric Materials, 56, 247-255 (2007).

[3] Poh B. T., Kwo H. K.: Peel and shear strength of pressure-sensitive adhesives prepared from epoxidized natural rubber. Journal of Applied Polymer Science, 105, 680-684 (2007).

[4] Poh B. T., Chow S. K.: Effect of zinc oxide on the viscosity, tack and peel strength of ENR 25-based pressure-sensitive adhesives. Journal of Applied Polymer Science, 106, 333-337 (2007). 
[5] Poh B. T., Kwo H. K.: Shear strength of SMR-based pressure-sensitive adhesives. Polymer-Plastics Technology and Engineering, in press (2007).

[6] Skeist I. E.: Handbook of Adhesives. Van Nostrand Reinhold, New York (1990).

[7] Sadequl A. M., Poh B. T., Ishiaku U. S.: Effect of filler loading on the mechanical properties of epoxidized natural rubber (ENR 25) compared with natural rubber (SMR L). International Journal of Polymeric Materials, 43, 261-278 (1999).

[8] Gierenz G., Karmann W.: Adhesives and Adhesive Tapes. Wiley-VCH, New York (2001).

[9] Poh B. T., Ong B. T.: Dependence of viscosity of polystyrene solutions on molecular weight and concentration. European Polymer Journal, 20, 975-978 (1984).
[10] Satas D.: Handbook of pressure-sensitive adhesive technology. Van Nostrand Reinhold, New York (1982).

[11] Barlow F. W.: Rubber Compounding: Principles, materials, and techniques. Marcel Dekker, New York (1988).

[12] Poh B. T., Ismail H., Quah E. H.: Fatigue, resilience and hardness properties of unfilled SMR L/ENR 25 and SMR L/SBR blends. Polymer Testing, 20, 389394 (2001).

[13] Poh B. T., Ismail H., Quah E. H., Chin P. L.: Cure and mechanical properties of filled SMR L/ENR 25 and SMR L/SBR blends. Journal of Applied Polymer Science, 81, 47-52 (2001).

[14] Lee L. H.: Adhesive bonding. Plenum Press, New York (1991) 